\title{
Förekomst av tretåig hackspett Picoides tridactylus på bestånds- och landskapsnivå
}

\author{
MARTIN AMCOFF \& PÄR ERIKSSON
}

\begin{abstract}
The Three-toed Woodpecker Picoides tridactylus has declined with at least fifty percent in most of Sweden since the 1970s. This study was made in a area of $150 \mathrm{~km}^{2}$ in the eastern part of the province of Uppland in order to explain the habitat requirements of the species at the levels of both forest stand and landscape. The amount of dead wood was strongly correlated with the occurrence of the woodpecker. The stage of decay of the tree seemed to be more important than the tree species, both for feeding and nest site selection. All breeding sites were surrounded by continuous forests of 100-400 ha characterized by low management intensity (trees older than normal final felling age, little thinning, and several features typical for a "natural" for-

est). In control areas of similar size but with normal management regimes, we found the Three-toed Woodpecker rare or absent. We also found that a high proportion of swamp forest partly could compensate shortage of dead wood in other forests. The species is able to respond rapidly when suitable habitats with many dead or dying trees appear after a distubance such as storm felling, insect attack, fire or flooding.

Martin Amcoff, Bernadottevägen 53 S-756 48 Uppsala, Sweden

Pär Eriksson, Funbo, Emilsgården, S-75597 Uppsala, Sweden
\end{abstract}

Received 14 June 1995, Accepted 3 December 1995, Editor: S. Svensson

\section{Inledning}

För att öka kunskaperna om den tretåiga hackspettens Picoides tridactylus status, populationsutveckling och biotopkrav påbörjade Naturskyddsföreningen ett projekt 1992 (projektledare Pär Eriksson). Denna uppsats är en delredovisning av detta projekt. Studier har utförts främst i östra Uppland och i Västerbottens kustland. För att komplettera bilden har också information insamlats från andra regioner i landet. Avslutningsvis ges i uppsatsen några rekommendationer för att förbättra situationen för den tretåiga hackspetten.

Tretåiga hackspetten häckar i Sverige från norra Götaland och norrut. Arten har minskat kraftigt under senare delen av 1900-talet och förekommer nu oregelbundet och sällsynt i södra delen av utbredningsområdet. Arten klassas som hänsynskrävande (hotkategori 4) men bedöms i ett regionalt perspektiv vara sårbar (hotkategori 2) i södra Sverige (Ahlén \& Tjernberg 1992).

De studier som utförts i projektets regi i södra Västerbottens kustland omfattar ca $450 \mathrm{~km}^{2}$. En minskning på uppskattningsvis $50 \%$ de senaste 10 åren inom detta område bedöms som rimlig (Eriksson 1994). I stora delar av Upplands skogsområden förekommer tretåiga hackspetten sparsamt till sällsynt. INorrtälje kommun bedöms beståndet av tretåig hackspett ha minskat till en tredjedel de senaste 25 åren (Douhan i brev 1992). I ett större skogsområde söder om Tämnaren i Uppland bedöms arten ha minskat till en fjärdedel sedan 1940-talet (Allan Lundin muntl.). Uppgifter från andra delar av landet talar om en liknande utveckling. Inom några undersökta områden i Norrbotten uppskattas arten ha minskat med ca 50\% sedan mitten av 1970-talet (Larsson 1994). I Dalarna talas om en minskning på 80\% de senaste 30-40 åren (Oldhammer 1991) och vid nedre Dalälven uppskattas minskningen till 50\% sedan mitten av 1970-talet (Holmstedt $1995 \mathrm{i}$ brev).

I många fall där häckande par försvunnit anges att avverkning av äldre och ogallrad grandominerad skog skett inom reviret. Även lövrika skogar med döda och döende träd uppges som en viktig och försvinnande miljö.

Mot bakgrund av tretåiga hackspettens tillbaka- 
gång, samt det faktum att mycket få studier av arten gjorts, är det angeläget att försöka följa artens utveckling och förhindra en fortsatt minskning.

\section{Metodilk}

\section{Kartläggning av landskap och skogsbestånd}

I denna uppsats redovisas i huvudsak resultat från studierna gjorda i östra Uppland 1993-1994. Inom ett $150 \mathrm{~km}^{2}$ stort område har landskapet karterats och indelats med avseende på skogens ålder, dominerande trädslag och inslag av sumpskog. En noggrann undersökning av skogens sammansättning och struktur i anslutning till boplatser har sedan utförts för att möjliggöra en analys av artens biotopkrav.

Under 1993-1994 studerades tretåiga hackspettens förekomst och biotopval i Vällenområdet i östra Uppland (Fig. 1). Ett $150 \mathrm{~km}^{2}$ stort skogsområde huvudsakligen öster om sjön Vällen flygbildtolkades och delades in i följande kategorier: skog över 50 år, sumpskog, ungskog, lövskog, hygge, åker och

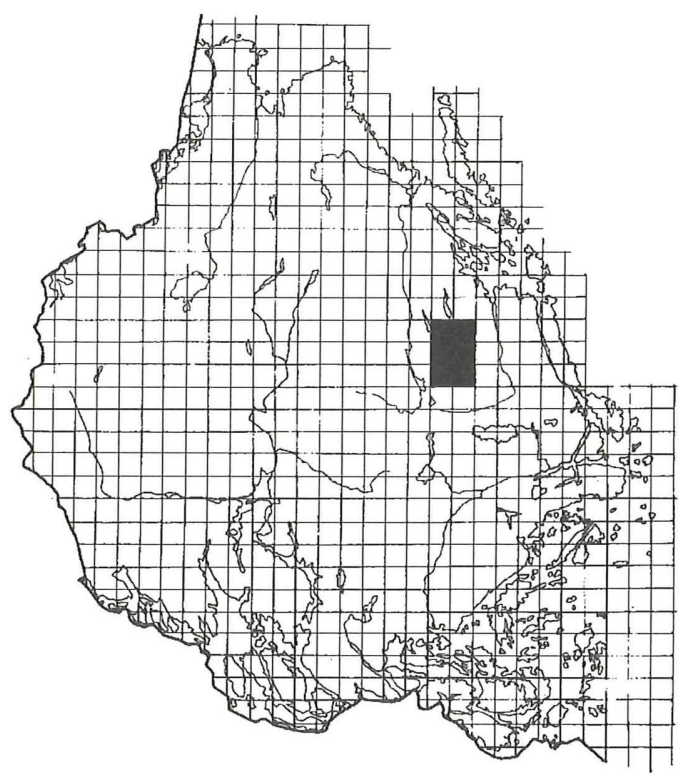

Fig. 1. Karta över Uppland där de sex rutor som utgör undersökningsområdet har markerats med svart. Rutsystemet är enligt rikets nät och varje ruta motsvarar ett ekonomiskt kartblad $\left(25 \mathrm{~km}^{2}\right)$.

The county of Uppland and the study area (marked black). Each grid square (plot) is $25 \mathrm{~km}^{2}$. vatten. För ändamålet användes IRF-bilder i skala 1:10.000 flygfotograferade 1992.

Utifrån flygbildstolkningen och tidigare kunskaper om området avgränsades de skogsområden där vi bedömde att tretåig hackspett kunde finnas. Detta innebar att alla tänkbara områden med skog över 50 år och sumpskog besöktes under trumningsperioden på våren. För att lättare lokalisera reviren användes ofta bandspelare. För att hitta boplatser och kunna konstatera häckningar genomströvades under maj och framförallt juni de områden där revir konstaterats under våren.

Vid de påträffade boplatserna gjordes mätningar av skogens sammansättning och struktur inom en cirkelyta med radien 399 meter utgående från boplatsen. Detta motsvarar en areal på 50 ha kring boplatsen och bör ge en uppfattning om skogens sammansättning och struktur i reviren. Mätningar gjordes inom varje enskilt skogsbestånd inom cirkelytorna. Mätytorna utgjordes av en cireklyta med 8 meters radie. Mätpunkterna valdes med utgångspunkt att ge en så sann bild av beståndet som möjligt på ett begränsat antal mätpunkter. Detta medförde att större bestånd och heterogena miljöer mättes på ett större antal punkter än små och homogena bestånd. Antal uppmätta ytor i varje enskilt bestånd var i allmänhet 3-5 men i små homogena bestånd var antalet färre. På de fyra boplatser som påträffades gjordes totalt 60 mätningar, som mest 20 och som minst 8 mätningar på en lokal. I några bestånd, vissa hyggen och unga trädplanteringar, utfördes inga mätningar, då ingen död ved fanns i bestånden och/ eller trädskikt saknades eller endast bestod av ett trädslag. De parametrar som undersöktes var volymen frisk och död ved, trädslagsfördelning, ålder, stamantal, diameter, höjd, markfuktighet, vegetationstyp och skogens slutenhet.

\section{Inventeringsmetodik}

Samtliga områden där tretåig hackspett bedömdes kunna finnas besöktes minst en gång och i många fall flera gånger från tidigt på morgonen fram till förmiddagen under trumningsperioden på våren 1993. Den totala inventeringstiden uppgick till 246 timmar och varierade mellan 28 och 53 timmar per $5 \times 5$ $\mathrm{km}$ ruta. Eftersom trumningsperiodens längd på morgonen vanligen är ganska kort användes bandspelare för att kunna fortsätta inventeringen framåt förmiddagen. Oparade fåglar svarade ofta energiskt på banduppspelning medan etablerade par i många fall endast svarade någon enstaka gång. Förekomst av hackmärken på framförallt granar men även tallar 
Tabell 1. Arealen skog över 50 år och sumpskog uttryckt i hektar i varje undersökningsruta $(5 \times 5 \mathrm{~km})$. Procentsiffrorna är baserade på landarealen. Längst ner i tabellen redovisas antalet tretåiga hackspettar i varje undersökningsruta.

Area in hectares of stands older than 50 years and swamp forests in each investigated plot (5x5 km). Figures in per cent are based on the total land area. At the bottom of the table, the total number of Three-toed Woodpeckers in each plot is shown.

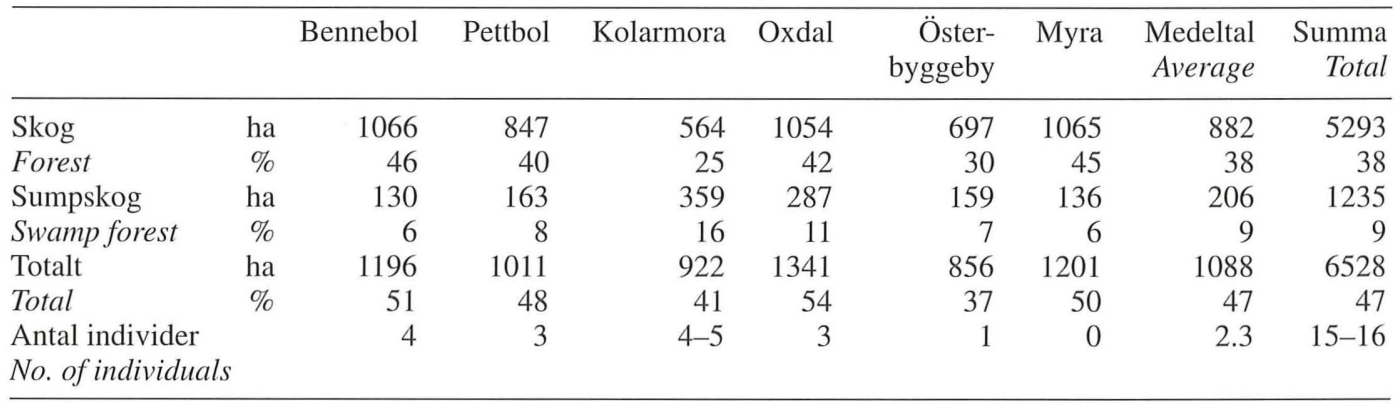

i några fall liksom de enskilda beståndens lämplighet för arten användes också för att effektivare söka besatta revir.

Under 1994 var avsikten att studera något eller några pars födosöksstrategi under häckningstid. I april kontrollerades två av de lokaler där häckning konstaterades 1993 samt en lokal med en ensam fågel. I juni genomfördes boletning vid de fyra lokaler där tretåig hackspett häckade året innan. Större skogsområden, ca 50-150 ha skog per lokal, genomströvades kring de fyra lokaler där häckning konstaterades 1993. Dessa områden inventerades med sådan noggranhet att mattiggande ungar skulle kunna höras. Vid flera av lokalerna gjordes besök både i början och slutet av juni med tyngdpunkten i mitten av månaden.

I samband med ovan beskrivna studier påträffades ibland födosökande fåglar. Från dessa tillfällen insamlades uppgifter om vilka trädslag som utnyttjades, trädens kondition, var på trädet födosöket skedde etc.

\section{Översiktlig beskrivning av undersökningsområdet}

Det inventerade området som är beläget vid sjön Vällen, ca $45 \mathrm{~km}$ nordost om Uppsala, har en total areal på $150 \mathrm{~km}^{2}$. Området är rektangulärt med sidorna $10 \times 15 \mathrm{~km}$ och omfattar 6 stycken $25 \mathrm{~km}^{2}$ stora rutor enligt rikets nät. Dessa är Bennebol 128 08, Pettbol 128 18, Kolarmora 128 28, Myra 12809 , Österbyggeby 12819 och Oxdal 12829.

Landarealen uppgår till $139 \mathrm{~km}^{2}$ och domineras starkt av skogsmark (ca 90\%) även om små och ofta igenplanterade åkrar, ett mindre antal gårdar samt öppna våtmarker förekommer. Öppna vattenytor utgör 7,4\% av inventeringsområdets areal. Landskapsbilden i stort karaktäriseras av barrdominerad skog på moränmark. Framförallt kring Vällens stränder förekommer betydande arealer lövskog eller skog med stort lövinslag. Skog över 50 år och sumpskog utgör 47,0\% av landarealen (Tabell 1) i hela inventeringsområdet, varav skog över 50 år utgör $38,1 \%$ och sumpskog $8,9 \%$. Ren lövskog täcker knappt en procent och är huvudsakligen samlad kring Vällens stränder. Omgivande landskap kring undersökningsområdet kan sägas ha likartad karaktär.

Större delen av arealen utgörs av rationellt brukad skog med jämn åldersfördelning i bestånden, låg andel död ved och få eller inga träd lämnade vid slutavverkning. Under de senaste åren har en påtaglig förändring skett och numera lämnas ofta ett betydande antal träd, huvudsakligen lövträd efter en slutavverkning. Flera större skogsområden med naturskogskaraktär förekommer också i området, framförallt i närheten av sjön Vällen. Av dessa naturskogsartade miljöer är ca 300 ha avsatta för fri utveckling inom tre naturreservat.

\section{Resultat}

\section{Förekomst av tretåig hackspett $i$ Vällenområdet} 1993

I inventeringsområdet påträffades sex par och minst tre ensamma individer. Fyra häckningar konstaterades och samtliga av dessa par fick ut flygga ungar. Ingen noggrann kontroll av häckningsresultatet gjordes men minimiantalet flygga ungar var 1,8 per 
häckande par. De två par för vilka häckning ej kunde konstateras observerades i april-maj men kunde ej återfinnas vid boletning under matningsperioden i juni. Om dessa par skred till häckning eller om häckningen misslyckades vet vi inte. Nämnas kan att en mård observerades alldeles intill ett av paren $\mathrm{i}$ slutet av april.

Av de sex påträffade paren förekom hela fem par på ett avstånd mindre än 1,5 km från Vällen. Ett häckande par fanns ca $4,5 \mathrm{~km}$ från sjön. De tre ensamma fåglar som hävdade revir var betydligt mer jämnt utspridda i undersökningsområdet och avståndet till Vällen var för dessa fåglar i genomsnitt $3,6 \mathrm{~km}$. Koncentrationen av par till Vällens närområde sammanfaller mycket tydligt med förekomsten av stora arealer äldre och ogallrade skogsområden.

Tätheten för par räknat på arealen skogsmark i undersökningsområdet var $0,05 \mathrm{par} / \mathrm{km}^{2}$. Räknar man in även ensamma revirhävdande fåglar blir tätheten 0,07 revir/ $\mathrm{km}^{2}$ skogsmark. Dessa tätheter är förmodligen bland de högsta i Uppland. Från Flororna i norra Uppland anges cirka 1 par per ekonomiskt kartblad om 25 km² (Jörgen Sjöström muntl.). Detta ger en täthet som motsvarar den i inventeringsområdet vid Vällen.

\section{Förekomst av tretåig hackspett $i$ relation till skogstillståndet inom inventeringsområdet}

Antalet observerade tretåiga hackspettar i relation till andelen skog över 50 år och sumpskog för varje undersökningsruta (ekonomiskt kartblad $5 \times 5 \mathrm{~km}$ ) framgår av Tabell 1. I fyra av de sex rutorna konstaterades häckning och totalt fanns minst 3-4 fåglar i varje sådan ruta. I de resterande två rutorna (Österbyggeby och Myra) fanns endast en ensam fågel som hävdade revir. Att dra några slutsatser om artens förekomst i relation till enbart andelen skog över 50 år och sumpskog är inte möjlig utan närmare studier på beståndsnivå.

\section{Biotopbeskrivningar av lokaler med tretåig hackspett}

Biotoperna i de revir där häckning konstaterades var förvånansvärt olikartade även om flera gemensamma nämnare fanns. Nedan ges först en allmän beskrivning av skogen kring de fyra häckplatserna och uppmätta värden av död ved i en cirkelyta på 50 ha kring boträdet. Därefter följer en översiktlig beskrivning av de områden där övriga par eller ensamma fåglar hävdade revir.
1. Lokal med konstaterad häckning (Pettbol 128 18) Paret vid Pettbol häckade på en sedan länge välkänd tretålokal i typisk miljö, nämligen naturskogsartad gammelgranskog med inslag av sumpskogspartier. Både i gran- och sumpskogen förekommer partier med stort lövinslag. Skogen utgörs av ett 150-300 meter brett och ca 800 meter långsmalt skifte som på båda sidor är omgivet av hyggen med ungskog. Tillgången på högstubbar, lågor, döda och döende träd är god. Mängden död ved i cirkelytan, vilken också i mycket stor utsräckning utnyttjades vid födosök, var 25,5 $\mathrm{m}^{3} \mathrm{sk} / \mathrm{ha}$ eller 9,9\% av virkesförrådet. Bo i grov och död granhögstubbe. Några 100 meter norr om skiftet finns större arealer äldre skog vilken bitvis är naturskogsartad. Det är troligt att denna skog utnyttjas som komplement kanske framförallt under vinterhalvåret.

\section{Lokal med konstaterad häckning (Oxdal 128 29)} Häckplatsen vid Oxdal utgörs av ett större skogsområde som domineras av 70-årig jämn granskog på fuktig mark vilken tidigare åtminstone delvis utgjorts av ängsmark. Ett flertal diken löper genom skogen och vissa partier är på gränsen att klassificeras som sumpskog. Trots den relativt låga åldern är andelen döda och döende granar bitvis relativt hög. Mängden död ved var 6,3 $\mathrm{m}^{3} \mathrm{sk} / \mathrm{ha}$ eller 2,0 \% av totala volymen. Detta är en relativt låg procentsiffra men den stora arealen äldre skog medför att mängden död ved totalt sett blir hög i cirkelytan (Tabell 2). Den exakta boplatsen hittades ej men en nyligen flygg ungfågel som matades av en hane sågs 24 juni. Skogen gränsar till sumpskog med betydligt högre andel död ved och till några yngre hyggen.

\section{Lokal med konstaterad häckning (Kolarmora 128 28)}

Vid Kolarmora skedde häckningen i en 90-årig ca 10 ha stor lövrik, ogallrad och dikningspåverkad sumpskog dominerad av gran, klibbal och björk. Skogen som till stor del växer på socklar är rik på högstubbar av klibbal och björk samt på döda granar. Mängden död ved i häckskogen var $23,0 \mathrm{~m}^{3} \mathrm{sk} /$ ha eller $7,7 \%$ av virkesförrådet. Omkring detta bestånd utbreder sig hyggen mestadels bevuxna med frodig gräs-, örtoch lövvegetation samt mer trivial barrskog. I hela cirkelytan på 50 ha kring boplatsen var andelen död ved $4,4 \%$. Boet var beläget $i$ en torrgran $\mathrm{i}$ kanten mot ett brett dike. 


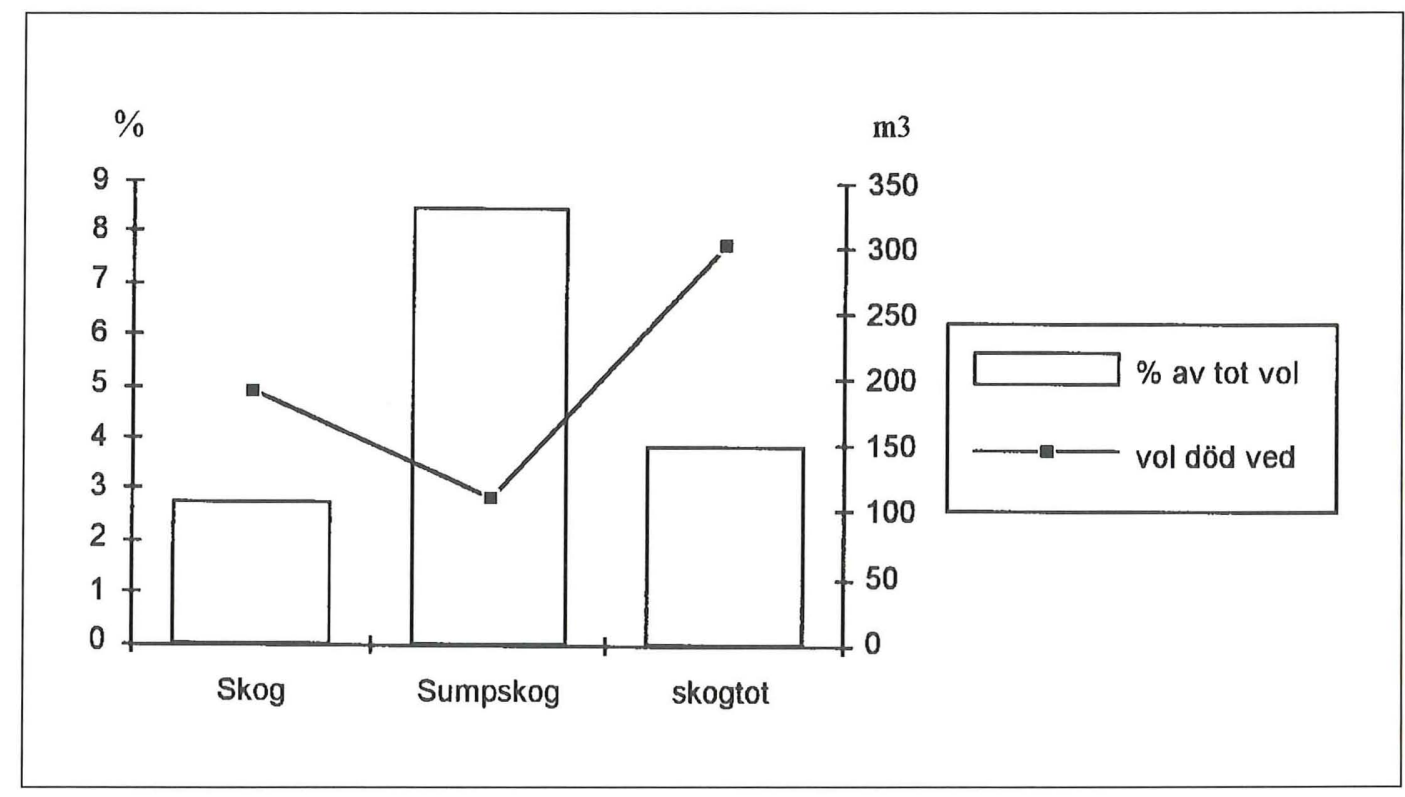

Fig. 2. Volymen död ved i cirkelytor (50 ha) kring de fyra häckplatserna fördelade på skog över 50 år och sumpskog samt totalt i skog och sumpskog. Staplarna visar den procentuella andelen död ved av totala virkesförrådet och linjen visar volymen död ved inom cirkelytorna. Observera att död ved i skog under 50 år och på hyggen ej ingår.

Volume of dead wood within circle areas (50 ha) around the four breeding sites shown separately for forest older than 50 years (Skog), swamp forest (Sumpskog), and both together (skogtot).

\section{Lokal med konstaterad häckning (Bennebol 128 08)}

Paret vid Bennebol häckade förvånansvärt nog i en välgallrad tallskog trots att stora arealer äldre naturskogsartad granskog fanns i närheten. Häcklokalen omgavs till tre fjärdedelar av nyupptagna hyggen där ett flertal träd och några mindre dungar lämnats. Två mindre sumpskogar hade blivit ytterligare försumpade efter avverkning med följden att ett större antal granar var döende eller hade dött. I en av sumpskogarna (0,6 ha) var andelen död ved hela $25,1 \%$ av virkesförrådet. Boet låg i en levande men rötad gran alldeles intill en väg. Förutom i sumpskogarna sågs paret ofta födosöka på hyggets granstubbar. I anslutning till reviret finns en sammanhängande medelålders och äldre skog på ca 400 ha. Denna skog i vilken Pansarudens naturreservat ingår är till stor del naturskogsartad och märken efter tretåig hackspett kan ses på ett flertal döda granar.

\section{Lokal med par (Kolarmora 128 28)}

Lokalen utgörs av en 70- till 90-årig ca 150 ha stor barrdominerad skog på frisk mark med inslag av ett större antal mindre sumpskogar och sumpdråg. Yng- re skog förekommer i liten omfattning. I kanten mellan skog på frisk mark och sumpskog samt i sumpskogen förekommer bitvis rikligt med döda träd. Förhållandevis stora arealer äldre ogallrad grandominerad skog förekommer.

\section{Lokal med par (Bennebol 128 08)}

Stora arealer naturskogsartad grandominerad skog med rikligt innehåll av död ved och försvagade träd. Större sumpskogar och områden med grov gammelgran. Det sammanhängande området med medelålders och äldre skog uppgår till ca 400 ha.

\section{Lokal med ensam hane (Oxdal 128 29)}

Ganska gammal granskog som inte gallrats pålänge. I anslutning till denna skog fanns ett relativt nyupptaget hygge.

\section{Lokal med ensam hane (Österbyggeby 128 19)} Fågeln uppehöll sig i ett område med större äldre barrdominerade skogspartier. I framförallt ett av skogspartierna finns naturskogsartade områden. Flera mindre sumpskogar. 
Tabell 2. Volym död ved i skog över 50 år och sumpskog inom cirkelytor (50 ha) vid 1993 års häckplatser. Inom parentes anges max- och minvärden för död ved inom cirkelytorna. Högre såväl som lägre andel död ved kan förekomma i de enskilda bestånden inom cirkelytorna. Längst till höger anges den procentuella andelen död ved av totala virkesförrådet.

Volume of dead wood in stands older than 50 years and swamp forests within circle areas (50 ha) around the breeding sites in 1993. Maximum and minimum values for dead wood within circle areas are shown within parentheses. In the right column the volume of dead wood of the total volume of trees is given.

\begin{tabular}{llll}
\hline & $\begin{array}{l}\text { död ved/ha } \\
\text { dead wood/ha } \\
\mathrm{m}^{3}\end{array}$ & $\begin{array}{l}\text { ved totalt } \\
\text { wood in total } \\
\mathrm{m}^{3}\end{array}$ & $\begin{array}{l}\text { \% död ved } \\
\text { \% dead wood }\end{array}$ \\
\hline $\begin{array}{l}\text { Skog Forest } \\
\text { Sumpskog Swamp forest }\end{array}$ & $8,2(1,8-18,9)$ & $192(35-352)$ & $2,8(1,0-5,6)$ \\
Totalt Total & $20,8(12,2-26,7)$ & $110(49-264)$ & $8,5(5,8-12,0)$ \\
\hline
\end{tabular}

\section{Lokal med ensam hona (Pettbol 128 18)}

Större områden med äldre ogallrad barrblandskog samt stora arealer sumpskog. Delvis god förekomst av död ved. Några år gammalt hygge med en del lämnade träd.

\section{Andelen död ved kring boplatserna}

De mätningar av skogens struktur som gjordes på de 50 ha stora cirkelytorna kring häckplatserna visade att samtliga häckplatser var belägna i områden med, i förhållande till landskapet omkring, hög andel död ved (Fig. 2). I medeltal var skogens innehåll av död ved $3,9 \%$ av totala volymen (Tabell 2). För de ingående sumpskogarna var andelen död ved 8,5\%. Enskilda sumpskogsbestånd kunde som mest ha en andel död ved på $25 \%$. Totalt sett var andelen död ved i medeltal $302 \mathrm{~m}^{3}$ med en variation mellan 180 och $479 \mathrm{~m}^{3}$ inom de 50 ha stora cirkelytorna kring boplatserna (Tabell 2).

Tyvärr gjorde vi inte några uppskattningar av andelen död ved utanför cirkelytorna runt boplatserna, men från Uppsala län som helhet har andelen död ved uppskattats till 1,5\%, d.v.s. mindre än hälften av den vid boplatserna (Svensson m.fl. 1989).

\section{Födosök}

Uppgifter om födosök har insamlats under häckningstid från undersökningsområdet vid Vällen 1993-94 och från Norrtälje kommun 1992. Materialet som baseras på 11 resp. 9 näringssök på träd eller lågor är begränsat men några förhållanden förtjänar att kommenteras. Det vanligaste sättet att söka föda var på trädstammar och under barken. Vid många tillfällen har fåglar som plockat insekter på barken och under barkflagor observerats. Vid två tillfällen noterades hack i veden och savsugningning förekom eventuellt på en tall Pinus sylvestris. Vid näringssök utnyttjades gran Picea abies (60\%), tall (20\%) samt björk Betula sp, asp Populus tremula och ek Quercus robur (vardera 6\%). Större delen av de träd som utnyttjades $(60 \%)$ var döda eller döende.

Ett flertal observationer har dessutom gjorts av fåglar som näringssökt på stubbar efter avverkning. Det par som häckade i Bennebol födosökte regelbundet på granstubbar på ett några år gammalt hygge. Häckplatsen var belägen i en trivial gallrad talldominerad skog mellan två nyupptagna hyggen där förhållandevis rikligt med framförallt asp samt några mindre sumpskogar lämnats. Delar av hyggena gränsade till stora sammanhängande äldre grandominerade skogar varför det var förvånande att finna häckplatsen i den "sämsta" skogen. Man kan anta att hygget utgjorde den viktigaste näringskällan under häckningstiden och att valet av boplats i hög grad styrdes av födotillgången.

Även den ensamma honan vid Pettbol sågs födosöka på stubbar och hyggesrester på ett par år gammalt hygge.

Studier av födosök har också gjorts i Västerbottens kustland. Även här dominerar gran (77\%) följd av gråal (15\%) och björk (8\%). Minst $85 \%$ av träden har varit döda eller döende (Eriksson 1993). Resultaten från Västerbotten tyder på att förutom gran också gråal utgör en viktig näringskälla kanske framförallt under vintern.

\section{Förekomst av andra hackspettar}

Av Tabell 3 framgår fördelningen av de hackspettarter som häckade i undersökningsområdet. Avsikten 
Tabell 3. Tätheten för de hackspettarter som förekom i undersökningsområdet 1993. Med skog avses här skog över 50 år inklusive lövskog samt sumpskog. Siffrorna uttrycker antal revir per ytenhet och innefattar såväl par som ensamma revirhävdande fåglar. För större hackspett, spillkråka och gröngöling är siffrorna baserade på ett $75 \mathrm{~km}^{2}$ stort område (rutorna Bennebol, Pettbol och Myra). För övriga arter är tätheterna räknade på arealen i hela undersökningsområdet.

Densities of woodpeckers in the study area in 1993. With forest means stands older than 50 years. Figures include pairs and single individuals.

\begin{tabular}{|c|c|c|c|}
\hline \multirow{2}{*}{$\begin{array}{l}\text { Art } \\
\text { Species }\end{array}$} & \multicolumn{2}{|c|}{ Revir $/ \mathrm{km}^{2}$ Territories $/ \mathrm{km}^{2}$} & \multirow[b]{2}{*}{$\begin{array}{l}\text { skog }>50 \text { år } \\
\text { forests }>50 \text { year }\end{array}$} \\
\hline & $\begin{array}{l}\text { skogsmark } \\
\text { forest }\end{array}$ & $\begin{array}{l}\text { total landareal } \\
\text { total land area }\end{array}$ & \\
\hline $\begin{array}{l}\text { Tretåg hackspett } \\
\text { Picoides tridactylus }\end{array}$ & 0,07 & 0,06 & 0,14 \\
\hline $\begin{array}{l}\text { Större hackspett } \\
\text { Dendrocopus major }\end{array}$ & 2,83 & 2,55 & 4,98 \\
\hline $\begin{array}{l}\text { Mindre hackspett } \\
\text { D. minor }\end{array}$ & 0,11 & 0,10 & 0,22 \\
\hline $\begin{array}{l}\text { Spillkråka } \\
\text { Dryocopus martius }\end{array}$ & 0,34 & 0,31 & 0,60 \\
\hline $\begin{array}{l}\text { Gröngöling } \\
\text { Picus viridis }\end{array}$ & 0,50 & 0,45 & 0,89 \\
\hline
\end{tabular}

med undersökningen i Vällenområdet var att studera förekomsten av tretåig hackspett vilket medförde att övriga hackspettarter inte blev lika noggrannt studerade varför täthetsuppskattningarna för dessa är mer osäkra. Antalet revir $/ \mathrm{km}^{2}$ skogsmark var för större hackspett 2,83 , gröngöling 0,50 , spillkråka 0,34 och mindre hackspett 0,11 . Koncentrationer av hackspettar fanns kring och på vissa nyupptagna hyggen där framförallt lövträd som asp och ek lämnats. Var skogen kring sådana hyggen dessutom varierad och innehöll en större andel blandskog och ogallrad skog påträffades ofta dessa arter häckande i träd som lämnats på hygget eller i nära anslutning till hygget. Som jämförelse kan nämnas att en inventering 1986 i Olas skifte, barrdominerad skog med bitvis betydande lövinslag, gav 13 bon av större hackspett på en areal av 1,3 $\mathrm{km}^{2}$ (Bill Douhan i brev).

\section{Boletning 1994}

Trots två veckors fältarbete under matningsperioden i juni kunde inga bon eller häckningar konstateras 1994. Vid kontroll i april av två av de lokaler där häckning konstaterades 1993 påträffades vid Brobol ett par och vid Olas skifte 1-2 ex, troligen ett par. Vid Olas skifte sågs en födosökande hona vid flera tillfällen i slutet av juni. Fågeln sågs även sitta högt upp i granar och vila och någon matning av ungar förekom inte. Vid Oxdal svarade en fågel kortvarigt vid uppspelning med bandspelare i början av juni. Ingen ytterligare kontakt erhölls med denna fågel. Vid 1993 års häcklokaler vid Kolarmora och Bennebol gjordes inga observationer i juni trots intensivt boletande.

\section{Förekomst $i$ Uppland}

Resultatet från Svensk fågelatlas 1974-1980-talet visar att tretåig hackspett förekommer i större delen av Uppland även om den saknas eller förekommer mycket glest i jordbruksområden. Förekomsten är splittrad och arten saknas också inom större skogsområden. En uppskattning av antalet par i Uppland på 1970- och början av 1980-talet utifrån inventering Svensk fågelatlas gav 90-100 par (Amcoff m. fl. 1985). Detta var förmodligen en underskattning av det verkliga antalet med tanke på att arten är svårinventerad och lätt förbises. Utifrån inventeringsresultaten vid Vällen kan en uppskattning av populationen i Uppland i dagsläge göras. För att erhålla ett underlag som är representativt för Upplands skogsmark i stort utgår vi från de tre östra inventeringsrutorna $\left(75 \mathrm{~km}^{2}\right)$. Inom dessa rutor bedrivis ett rationellt skogsbruk på större delen av arealen och de naturskogsartade bestånden är få. I detta område var tätheten $0,015 \mathrm{par} / \mathrm{km}^{2}$ skogsmark vilket omräknat till Uppsala län, Heby och Norrtälje kommun ger totalt 93 par. Inom stockholmsdelen av 
Uppland bedöms ytterligare cirka fem par finnas. Populationen i Uppland skulle därmed kunna skattas till cirka 100 par.

\section{Diskussion}

\section{Inventeringsresultat}

Vår uppfattning är att vi fick kontakt med så gott som samtliga fåglar i inventeringsområdet. Det är dock inte helt uteslutet att någon eller något fătal fåglar kan ha undgått oss. Ett problem vid utvärderingen av resultaten var i flera fall att skilja ut olika individer och par där dessa förekom i angränsande revir. Vår uppfattning är att tretåig hackspett är en svårinventerad art bland annat beroende på att framförallt etablerade par i vissa fall är mycket tysta och tillbakadragna. Fåglarna rör sig över stora skogsområden och är såvida de inte trummar eller lockar mycket svåra att hitta.

\section{Krav på landskapsnivå}

Om man jämför de båda angränsande rutorna Myra och Bennebol (Tabell 1) finner man att andelen skog och sumpskog är närmast identisk, rutorna har den högsta andelen skog över 50 år (45,6 resp 44,8\%) och den lägsta andelen sumpskog (5,6 resp 5,7\%). Men rutan Bennebol hyste minst 4 tretåiga hackspettar medan ingen fanns i Myra (Tabell 1).

Skillnaden i förekomst av tretåig hackspett mellan Bennebol och Myra beror uppenbarligen inte på brist på skog utan snarare på brist på lämplig skog. Inom Myrarutan är skogarna i allmänhet relativt jämnåriga och oftast gallrade med följden att andelen död ved och träd med nedsatt kondition är låg. Områden med äldre ogallrad skog förekommer men arealen är mycket liten.

I rutan Bennebol är förhållandena de motsatta. Här finns ovanligt stora arealer (hundratals hektar) äldre ogallrad grandominerad skog, vilken på betydande arealer kan karaktäriseras som naturskog. Andelen död ved och träd i dålig kondition är i dessa skogar hög. Det var därför något överraskande att boplatsen vi fann var belägen i gallrad trivialskog där reviret till stor del utgjordes av nyupptagna hyggen. Att häckning skedde just i detta område kan förmodligen förklaras av den rika tillgång på föda i form av vedinsekter som uppenbarligen fanns i stubbar och hyggesavfall något år efter avverkningen. Detta par sågs också födosöka på stubbar på hygget under hela häckningsperioden. Mängden död ved i cirkelytan kring häckplatsen var den lägsta av alla häckplatserna (Fig. 3). Skulle man räkna in stubbarnas virkesvolym skulle siffran för död ved stiga med flera $100 \mathrm{~m}^{3}$. I anslutning till hygget fanns dessutom en sumpskog där vattennivån höjdes efter avverkningen och ett stort antal barrträd dog. Även denna lokal nyttjades flitigt för furagering. Det bör också poängteras att detta revir ligger i anslutning till ett mer än 400 ha stort sammanhängande område med medelålders och äldre skog vilken till stor del är av naturskogskaraktär.

Ser man på rutan Kolarmora som hyste 4-5 tretåiga hackspettar så är andelen skog över 50 år den lägsta, endast $25,3 \%$, medan andelen sumpskog är den högsta, hela $16,1 \%$. Trots den mycket låga andelen skog över 50 år hyste denna ruta flest individer. Orsakerna till detta kan förklaras av flera förhållanden. Mätningar av andelen död ved kring häckplatsen (cirkelyta 50 ha) visade att sumpskogarna i medeltal höll 8,5\% död ved av totala virkesförrådet medan motsvarande siffra för skog över 50 år var 2,8\% (Fig. 2). Boplatsen vid Kolarmora var belägen i en större sumpskog vilken innehöll 27 $\mathrm{m}^{3}$ sk död ved/ha eller 7,5\% död ved av totala virkesförrådet. Den kringliggande skogen över 50 år i cirkelytan innehöll endast 1,0\% död ved. Den förhållandevis höga andelen sumpskog har med all sannolikhet en helt avgörande betydelse för arten inom denna ruta och uppväger den låga andelen äldre skog. Vid häckplatsen, där för övrigt ytterligare ett par sågs, finns också ett större (ca 300 ha) sammanhängande område med äldre skog i ett i övrigt hårt hugget landskap.

Den häckplats som uppvisar högsta andelen död ved är inte helt överraskande Olas skifte (Pettbol) som till stor del utgörs av gammal naturskog omfattande ca 140 ha. I detta område har för övrigt tretåig hackspett årligen dokumenterats under en längre tid.

Förekomsten av tretåig hackspett i relation till skogens sammansättning och struktur framträder tydligast om man jämför två cirka $50 \mathrm{~km}^{2}$ stora delområden i sydöstra respektive västra delen av undersökningsområdet. Det sydöstra delområdet utgörs till helt övervägande del av rationellt brukad skog. En lika stor areal i undersökningsområdets västra del vid Vällenstranden uppvisar stora sammanhängande arealer äldre skog vilken skötts med låg skogsbruksintensitet eller på betydande arealer fått utvecklas fritt under lång tid. I den sydöstra delen påträffades ingen tretåig hackspett 1993 medan den västra delen hyste 5 par och ytterligare 1-2 individer. Markförhållanden, topografi m.m. skiljer sig inte mycket mellan de jämförda lokalerna utan det är skogsbrukets varierande intensitet som skapat 

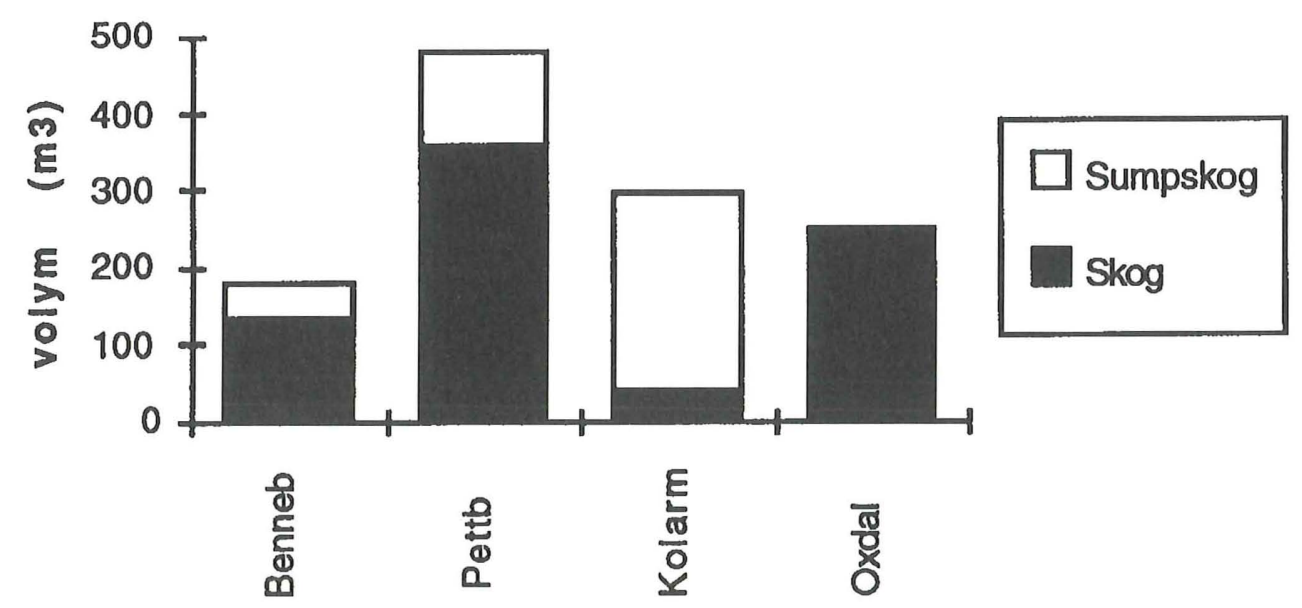

\section{revir}

Fig. 3. Volym död ved i skog över 50 år och sumpskog inom varje cirkelyta (50 ha) kring de fyra häckplatserna.

Volume dead wood in forest older than 50 years and swamp forest within each circle area (50 ha) around the four breeding sites.

den stora skillnaden i skogens sammansättning och struktur. Den markanta skillnaden i förekomst mellan de båda delområdena indikerar starkt att arten missgynnats av ett rationellt skogsbruk där ogallrade och äldre skogar inte förekommer.

Tretåig hackspett har tidigare häckati den sydöstra delen. Under 1980-talet fanns arten på minst en lokal men har försvunnit sedan betydande arealer äldre skog avverkats (Peo Westman muntl.). Vid inventeringen 1993 hittades på en annan lokal i den sydöstra delen av undersökningsområdet ringbarkade träd och relativt färska hackmärken. På denna lokal hade en del av den äldre skogen avverkats under föregående vinter och med tanke på det omgivande lanskapets låga andel äldre skog är det troligt att arten ej längre kunde klara sig på denna lokal. Vidare finns en observation av ett par i området 30 augusti 1974. Även om observationen är gjord relativt sent på säsongen kan den mycket väl tyda på att arten häckat vid eller i närheten av denna lokal.

Populationen i Uppland tycks vara koncentrerad till vissa kärnområden. Uppskattningsvis finns $40 \%$ av beståndet i tre större områden, nedre Dalälven,
Florarna och Vällenområdet. Denna fördelning tyder på en viss fragmentering och koncentration till områden där länets största naturreservat av skogsmark är belägna.

\section{Krav på beståndsnivå och landskapsnivå}

Utifrån resultaten av skogens struktur kring häckplatserna och skogstillståndet i hela undersökningsområdet samt fördelningen av par och ensamma fåglar kan några faktorer som är avgörande för artens existens i området ställas upp.

(1) Stor areal sammanhängande äldre skog I eller i direkt anslutning till samtliga revir fanns stora sammanhängande äldre skogsområden. Inom de revir där häckning skedde eller par observerades var den sammanhängande arealen äldre skog ca 100-400 ha. På de platser där ensamma fåglar hävdade revir var tendensen att den sammanhängande arealen äldre skog var mindre medan stora sumpskogar av varierande kvalitet ofta fanns som komplement. Karaktäristiskt för de större skogsområdena 
kring reviren var att skogsbruksintensiteten var låg eller obefintlig på betydande arealer.

Det är troligt att äldre ogallrade skogar är helt nödvändiga för artens existens kanske framförallt under vinterhalvåret. Under denna tid försvåras sannolikt födosök på exempelvis nya hyggen av snötäcket. Gammelskogen kan också ha stor betydelse under delar av häckningssäsongen inte minst vid dåligt väder. Resultaten från de övriga häckplatserna i undersökningsområdet och observationer från andra häckplatser visar att äldre ogallrad skog i allmänhet är den viktigaste födosöksbiotopen under häckningstid (se Douhan 1989).

\section{(2) Hög andel död ved}

All skog över 50 år och sumpskog i cirkelytor kring häckplatserna innehöll i medeltal 3,9\% död ved av totala virkesförrådet. Totala volymen död ved varierade inom motsvarande områden mellan 180 och $479 \mathrm{~m}^{3}$ (Fig. 3). Andelen död ved i sumpskogarna var $8,5 \%$ och i övrig skog över 50 år $2,8 \%$. I cirkelytorna kring häckplatserna ingick ofta arealer med kulturskog vilken innehåller mycket lite död ved och troligen inte utnyttjas i särskilt stor utsträckning vid födosök. I reviren fanns ofta enskilda bestånd med mycket hög andel död ved, som mest kring 25\%. Hög andel död ved påträffas mycket sällan i kulturskogarna utan förekommer i äldre naturskogsartad skog och i ogallrade bestånd i övrigt. Lokalt kan större mängder död ved finnas t.ex. genom stormfällning längs hyggeskanter och vid försumpning i samband med avverkningar.

Reviret vid Bennebol uppvisar den klart lägsta mängden död ved vilket sannolikt kompenserades av de stora mängder död ved som fanns på de nyupptagna hyggena inom reviret och i den anslutande tillfälligt "översvämmade" sumpskogen.

I gallrad kulturskog är andelen död ved i allmänhet mycket låg och anges till mindre än $2 \% \mathrm{i}$ genomsnitt (SNV 1994). Det förefaller troligt att den tretåiga hackspetten inte kan existera i sådan skog mer än tillfälligtvis.

\section{(3) Sumpskogar}

Sumpskogarna i anslutning till häckplatserna innehöll procentuellt sett betydligt högre andel död ved än fastmarksskogen, 8,5\% jämfört med 2,8\%. Naturskogsartade och äldre fastmarksskogar har i allmänhet högre total virkesvolym än sumpskogar och kan därför absolut sett hålla en större volym död ved. Dessa typer av skogar förekom också på betydligt större arealer inom de tänkta reviren varför mängden död ved totalt sett blir större än i sumpskogen (Fig.
2). Undantag var häckplatsen vid Kolarmora där häckningen skedde i en större volymrik sumpskog av högörttyp (Fig. 3). På denna lokal får sumpskogen anses ha en helt avgörande roll. Den höga andelen sumpskog kompenserar sannolikt bristen på äldre skog inom denna ruta som hyste flest individer av arten inom hela undersökningsområdet. Vid Bennebolreviret var arealen sumpskog mycket låg men av mycket hög kvalitet (nyligen döda granar efter försumpning). Inom cirkelytan vid häckplatsen Oxdal förekom ingen egentlig sumpskog men marken var flerstädes fuktig och skogen där på gränsen till sumpskog. Dessutom gränsade detta revir till en större sumpskog med hög andel död ved.

\section{(4) Störningsmiljöer}

Störningar som ger upphov till ökad mängd försvagade och döda träd är av central betydelse för tretåiga hackspettens existens. Det tycks också vara så att arten mycket snabbt svarar på lokala störningar som medför ökad andel döda träd. Den artificiella störning som ett hygge utgör kan åtminstone temporärt vara positiv för tretåiga hackspetten särskilt om enstaka träd, skadade träd och mindre dungar lämnas orörda. Det tidigare beskrivna paret i Bennebol som häckade i en trivial skog mellan två nyupptagna hyggen där en stor del av födosöket skedde just på hyggen ger stöd för detta. I en naturskog är andelen död ved hög genom självgallring men även här har störning t.ex. genom stormfällning och avblåsta träd stor betydelse. En undersökning från norra Finland visade att tätheten av häckande tretåiga hackspettar i ett skogsområde ökade signifikant efter en omfattande stormfällning (Virkkala m.fl. 1991). Flera uppgifter om förekomster i nyligen bränd skog finns. I Värmland brann två skogsområden hårt sommaren 1992. Bränderna omfattade ca 30 ha respektive 100 ha medelåldrig talldominerad skog. Lokalerna var väl kända och hyste inga tretåiga hackspettar före branden. Redan samma år var båda brandfälten väl frekventerade av ett stort antal hackspettar, framför allt spillkråka och tretåig hackspett. På den större lokalen sågs upp till tio individer av tretåig hackspett samtidigt (Jan Bengtsson muntligen). Även året efter fanns tretåig hackspett kvar och parbildning konstaterades med säkerhet på en av lokalerna (Torbjörn Westerberg i brev). År 1994 var bara en individ kvar vid de båda brandfälten. De båda brandfälten lämnades i hög grad orörda efter branden och de brända trädstammarna var så gott som alla angripna av födosökande hackspettar 1994. Även från Hälsingland uppges flera lokaler med nybränd skog hysa arten (Wikars 1991 i brev), liksom i södra 
Småland där en hane observerades våren 1994 på ett nytt brandfält (Vakö myr) där den tidigare saknats (S. G. Nilsson 1995 pers. med.). Sannolikt är även tillfälligt översvämmad skog i anslutning till bäverdämmen en miljö som gynnar arten.

\section{(5) Lövträd}

Den tretåiga hackspetten är kanske mer gynnad av lövträd än vad man i regel trott. I Västerbotten tillhör alstrandskogen längs den flacka kusten en av de viktigaste biotoperna för arten med rik tillgång på döda och döende lövträd där näringssök sker frekvent framför allt under vinterhalvåret (Olsson 1993). I Norrbotten anger flera uppgiftslämnare aspen som det dominerande trädslaget som boträd (Larsson 1994). Asp är även konstaterad som boträd vid flera tillfällen vid nedre Dalälven. Även i Vällenområdet har vi kunnat konstatera flera näringssök på olika lövträd. Det förefaller sannolikt att trädets kondition och ålder, både vad gäller födosök och bobygge, i många fall är mer avgörande för den tretåiga hackspetten än trädslaget i sig.

\section{Boletning 1994}

Av de fem lokaler som kontrollerades 1994 konstaterades par eller enstaka fåglar på fyra av dessa lokaler. Revirhävdande par fanns med säkerhet vid Bennebol och troligen också vid Olas skifte. Kolarmora och Oxdal kontrollerades ej under våren varför par mycket väl kan ha funnits här. Vid Oxdal observerades också en fågel $\mathrm{i}$ början av juni. Trots intensiv boletning under matningsperioden i juni kunde inga häckningar konstateras. Orsakerna till detta kan vara många. Skedde häckningarna utanför de undersökta områdena, missade vi bon med ungar trots noggrann kontroll eller var det så att många par misslyckades med häckningen. Kanske hade det kyliga och ostadiga vädret i maj och början av juni negativ inverkan på häckningsresultatet. Att häckningar misslyckats eller uteblivit indikeras av den hona som sågs födosöka och vila vid Olas skifte under lång tid den 23 juni.

Även i Norrbotten tycks arten fluktuera i antal mellan olika år (Larsson 1994). Hackspettinventeringar från västra Värmland antyder samma sak (Eriksson 1994).

\section{Skogsbruket och den tretåiga hackspettens framtid}

Skogsbruket har under lång tid förändrat skogarna på många sätt. Genom att stora arealer fuktig och blöt mark dikats ut har vattenståndsfluktuationerna och därmed översvämningarna minskat kraftigt. Röjning, gallring och slutavverkning när skogen nått ekonomisk mognad har inneburit att variationen i skogen sjunkit avsevärt och andelen död ved blivit mycket låg. De förr regelbundet återkommande skogsbränderna, vilka genom att döda och försvaga träden skapade gynsamma miljöer för arten, är idag mycket ovanliga.

Kommer den ökade hänsynen inom skogsbruket att förhindra en fortsatt minskning av beståndet av tretåig hackspett eller kommer arten att försvinna inom stora delar av utbredningsområdet? Något entydigt svar finns knappast på frågan. Ett allvarligt problem kan vara fragmenteringen av skogslandskapet där avstånden mellan större naturskogsartade bestånd blir så stort att en livskraftig population ej längre kan finnas kvar i landskapet. Resultatet från inventering "Svensk fågelatlas" 1974-1980-talet visar att tretåig hackspett förekommer i hela Uppland även om den saknas eller förekommer mycket glest i slättdominerade områden som kring Uppsala och i sydvästra Uppland. Arten förefaller också saknas i flera större skogsområden. Koncentrationer av fåglar liknande den kring Vällen förekommer i övriga Uppland så vitt är känt endast i Flororna och vid Nedre Dalälvren. I övrigt är tendensen att enstaka spridda par lever kvar i "gammelskogar" där de i många fall funnits under lång tid. Det finns skäl att tro att populationen i Uppland är på väg att bli eller kanske redan är fragmenterad i några större kärnområden med en starkt utglesad stam mellan dessa.

Tretåiga hackspetten tycks ha minskat med 50$80 \%$ inom stora delar av Sverige under de senaste 20-30 åren. För att motverka den negativa trenden för arten är det nödvändigt att arten uppmärksammas mer i samband med skogliga åtgärder och bildande av naturreservat.

\section{Rekommendationer för att gynna tretåig hackspett}

- Öka andelen äldre skog som får utvecklas fritt. Huvudsakligen äldre naturskogsartad barrskog, lövbrännor, strandskogar och sumpskog. Enskilda skogsbestånd bör helst vara minst100 ha.

- Lämmna enskilda träd och grupper på hyggen liksom vindfällen.

- Lämna undertryckta träd och klena senväxande granar vid förrensning och gallring.

- Lämna sumpskogar, surdråg och strandskogar orörda.

- Öka lövandelen generellt, liksom inslaget av död ved.

- Utnyttja skärmföryngring på fuktig mark som ger 
en ökad andel död gran och förekomst av granbarkborrar.

- Öka antalet naturvårdsbränningar med kvarlämnade döda träd. Objekten kan vara relativt små ( $<5$ ha) men ha stor betydelse under en kortare tid.

\section{Tack}

Projektet har finansierats genom medel från Naturskyddsföreningen, Upplandsstiftelsen och Alvins fond. Ett tack riktas till Christer Olsson, Ulrik Lötberg, Owe Rosengren, Björn Svensson, Peo Westman, Stefan Karlsson och Kjell-Arne Larsson vilka deltagit $\mathrm{i}$ inventeringsarbetet och bidragit med uppgifter till denna sammanställning.

\section{Referenser}

Ahlén, I. \& Tjernberg, M. 1992. Artfakta. Sveriges hotade och sällsynta ryggradsdjur. Sveriges lantbruksuniversitet, Uppsala.

Amcoff, M., Douhan, B., Edholm, M., Granberg, B., Tjernberg, M \& Westin, P. 1985. Fågelrapportering i Uppland 1984. Fåglar $i$ Uppland 12:112-150.

Anderson, M. 1991. Tretåig hackspett - biotopval i västra Västmanland. Pandion 7:1-9.

Eriksson, P. 1993. Preliminär rapport från Projekt tretåig hackspett. Naturvårdsverket, Alvins fond.

Eriksson, P. 1994. Rapport från Projekt Vitryggig hackspett 1994. Naturskyddsföreningen.

Douhan, B. 1989. Vad händer under ett dygn vid den tretåiga hackspettens bo? Fåglar i Uppland 16:115-125.

SNV. 1994. Biologisk mångfald i Sverige. Monitor 14. Statens naturvårdsverk.

Svensson, S. A., Toet, H. \& Kempe, G. 1989. Riksskogstaxeringen 1978-82. Sveriges lantbruksuniversitet, Umeå.

Virkkala, R., Heinonen, M. \& Routasuo, P. 1991. The response of northern taiga birds to storm disturbance in the Koilliskaira National Park, Finnish Lapland. Ornis Fennica 68:123-126.

Larsson, F. 1994. Lite om tretåig hackspett $i$ Norrbotten. Naturvårdsverket, Alvins fond.

Olsson, C. 1993. Avrapportering till Projekt tretåig hackspett. Naturskyddsföreningen.

Oldhammer, B. 1991. Tretåig hackspett. Björnramen, Nr. 3. Naturskyddsföreningen i Mora.

\section{Summary}

Occurrence of Three-toed Woodpecker Picoides tridactylus at the scales of forest stand and landscape

The Three-toed Woodpecker has declined with at least fifty percent in large parts of Sweden since the 1970s. An exception is possibly the populations in the subalpine birch woods and the coniferous forests near the montain range in the northen part of the country.

In 1992 the Swedish nature conservation society initiated a project on the Three-toed Woodpecker with one of the authors (Pär Eriksson) as project leader. This report gives the results obtained in 1993-1994 within an area of $150 \mathrm{~km}^{2}$ in the eastern part of the province of Uppland (Fig. 1) where we aimed at defining the habitat requirements of the species at the scales of both individual forest stand and landcape.

We analysed aerial photographs (1:10,000 from 1992) and delimited possible habitats for the Threetoed Woodpecker (forest older than 50 years and swamp forest). These areas were searched during the spring drumming period (sometimes using tape recordings) and, for nests, in May and June. Around each of four nest sites we established a circular area of 50 ha. Within each such area we sampled all different forest types using a total of 60 circular plots with a radius of $8 \mathrm{~m}$. Recorded variables were volume living and dead wood, tree species, age, number of trees, height, ground moisture, type of ground vegetation, and canopy density.

The total land area was $139 \mathrm{~km}^{2}$ (93\% of the total study area) and $90 \%$ of the land area was forest. 47 $\%$ of the land area was forest older than 50 years $(38 \%)$ or swamp forest (9\%) (Table 1). Most land was ordinary managed forest, but there were also several fairly large areas with forest of a more "natural" type, and also 300 ha of nature reserves with forest under free development.

We located six pairs and at least three single individuals of Three-toed Woodpecker, and we found four nests.

We did not find any correlation between the number of woodpeckers and the area of forest older than 50 years or with the area of swamp forest when we compared the six study squares (Table 1). Hence, the key factors must operate on a scale smaller than that of the landscape.

The amount of dead wood was strongly correlated with the abundance of the species. All territories were found within forest with much more dead wood than in the other parts of the study area. Within the 50 ha circular plots around the nests, the proportion of dead wood was $3.9 \%$ of the total wood volume. In the swamp forest parts it was as high as $8.5 \%$. The proportion of dead wood in the feeding areas was probably still higher. The corresponding figure for the whole of the county is only $1.5 \%$. The decay stage and age of the trees seemed to be more impor- 
tant than the species of trees both for feeding and nest site selection.

In our study area, the Three-toed Woodpecker was found in large continuous forests with low management intensity, i.e. little thinning and a high proportion of trees older than the normal age of final felling. At all breeding sites there were continuous forest stands of 100-400 ha. Considerable proportions of these stands had a character of "natural forest" and delayed thinning. Similar observations have been made in other parts of the country.

Large, continuous forests with normal management regimes of thinning, clear felling and planting were found in many parts of the study area. These forests contained stands of even age, had few dead or dying trees and were not permitted to grow old. In these forests we found seldom or never any Threetoed Woodpeckers.

We found that swamp forest in connection with larger, coniferous stands could be important for the species, and it appeared as if swamp forest could parly compensate a shortage of old forest.

The Three-toed Woodpecker seems to be sedentary as long as suitable conditions prevail, but responds also rapidly when new, good habitats are created by disturbances such as insect attack, storm felling, fire, or flooding.
In the province of Uppland the species depends to a large extent on forest areas with a high proportion of nature reserves.

In order to support the Three-toed Woodpecker and turn the negative trend to a positive one we recommend as follows:

- Increase the proportion of old forest under free development, primarily forest which already has many features of a "natural" forest, riverine forest, and swamp forest. Individual forest stands should preferably be at least 100 ha.

- Leave single trees and groups of trees on clearfelled areas as well as storm fellings.

- Leave supressed trees and slowly growing spruces when thinning.

- Leave swamp forests, small swampy patches within forest, and riverine forests.

- Increase generally the proportion of broad-leaved trees as well as the amount of dead wood.

- New plantations on moist ground should be made under a shield of old trees. This creates a larger proportion of dead spruces and richer occurrence of bark beetles.

- Increase the number of controlled management fires and leave dead trees. Such woods may be rather small ( $<5 \mathrm{ha}$ ) but may still be important for a brief period of time. 